\title{
Questionnaire survey on the management of pregnant women with preterm premature rupture of membranes
}

\author{
Seo Yeon Kim, PhD ${ }^{1,2}$, Han Sung Kwon, MD, PhD ${ }^{1,3}$, Jayeon Lee, $\mathrm{PhD}^{4}$, Ah Ram Sul, $\mathrm{PhD}^{4}$, \\ Hyun Sun Ko, MD, PhD ${ }^{5}$, Jeong In Yang, MD, $\mathrm{PhD}^{6}$ \\ ${ }^{1}$ Division of Maternal and Fetal Medicine, Department of Obstetrics and Gynecology, Research Institute of Medical Science, Konkuk University, School \\ of Medicine; Department of Obstetrics and Gynecology, ${ }^{2}$ Samsung medical Center, Sungkyunkwan University, School of Medicine, ${ }^{3}$ Konkuk University, \\ School of Medicine; ${ }^{4}$ National Evidence-based Collaborating Agency; Department of Obstetrics and Gynecology, ${ }^{5}$ College of Medicine, The Catholic \\ University of Korea, Seoul, ${ }^{6}$ Ajou University, School of Medicine, Suwon, Korea
}

\section{Objective}

The aim of this survey was to study the status of the actual practice in the management of preterm premature rupture of membranes (PPROM) between 34.0 and 36.6 weeks of gestation.

\section{Methods}

This survey was designed for obstetricians who work in secondary or tertiary medical institutions and attended the Korean Society of Maternal Fetal Medicine conference held on July 1, 2017, in Korea, using a structured questionnaire consisting of 5 questions.

Results

The most commonly used antibiotic was cephalosporin monotherapy (34.5\%). Antenatal corticosteroids were applied up to 34.0 weeks of gestation in half of the respondents. The frequency of expectant management was higher than that of immediate delivery in women with PPROM between 34.0 and 36.6 weeks of gestation (57.4\%). The most important factor in determining immediate delivery was the symptoms of chorioamnionitis.

\section{Conclusion}

The present survey showed a considerable variation in the actual management of PPROM in women, especially the optimal timing of delivery. More evidenced-based studies with statistical power are required to decrease the heterogeneity of clinical practice.

Keywords: Fetal membranes, premature rupture; Antibacterial agents; Betamethasone; Dexamethasone; Delivery, obstetric

\section{Introduction}

Premature rupture of membranes (PROM) is defined as rupture of the amniotic membrane prior to labor, which occurs in approximately $20 \%$ of all pregnancies [1]. If PROM occurs during term, immediate delivery is recommended, as it is associated with a significantly lower perinatal morbidity rate than expectant management [1-4]. However, the management of women with preterm PROM (PPROM), accounting for $40 \%$ of the total preterm deliveries, is somewhat controversial. Immediate delivery may lead to complications resulting from fetal immaturity, but expectant management
Received: 2019.08.26. Revised: 2019.10.22. Accepted: 2019.11.13. Corresponding author: Jeong In Yang, MD, $\mathrm{PhD}$

Department of Obstetrics and Gynecology, Ajou University Medical School, 164 Worldcup-ro, Yeongtong-gu, Suwon 16499, Korea

E-mail: yangji@aumc.ac.kr https://orcid.org/0000-0001-5646-9009

Han Sung Kwon, MD, PhD

Department of Obstetrics and Gynecology, Konkuk University, School of Medicine, 120-1 Neungdong-ro, Gwangjin-gu, Seoul 05030, Korea

E-mail: 20050024@kuh.ac.kr

https://orcid.org/0000-0002-4449-0481

Articles published in Obstet Gynecol Sci are open-access, distributed under the terms of the Creative Commons Attribution Non-Commercial License (http://creativecommons. org/licenses/by-nc/3.0/) which permits unrestricted non-commercial use, distribution, and reproduction in any medium, provided the original work is properly cited.

Copyright $\odot 2020$ Korean Society of Obstetrics and Gynecology 


\section{Obstetrics \& Gynecology Science}

Seo Yeon Kim, et al. Survey on the management of PPROM

is associated with risks such as placenta abruptio, infection, fetal distress, and umbilical cord prolapse, causing a medical dilemma $[2,5,6]$. In early PPROM, defined as PROM before 34.0 weeks of gestation, expectant management is strongly recommended because of adverse neonatal outcomes from prematurity. In a study of Ekin et al. [7], although complications such as chorioamnionitis and placental abruption were increased, the overall adverse pregnancy outcomes were decreased in women managed expectantly. The optimal management of late PPROM, defined as PROM between 34.0 weeks and 36.6 weeks of gestation, remains inconclusive. Therefore, the management of late PPROM should be determined on the basis of a comprehensive acknowledgment of the risk of infection and possible complications from premature delivery. According to the 2018 American College of Obstetricians and Gynecologists (ACOG) guidelines [1,8], expectant management, including a combination therapy of intravenous ampicillin and erythromycin, administration of antenatal corticosteroids until 34.0 weeks of gestation and group B Streptococcus prophylaxis, is strongly recommended. The guidelines recommend prompt delivery after 34.0 weeks of gestation. However, the Cochrane review mentioned the lack of clinical evidence to support these guidelines $[2,8]$ The 2018 ACOG guideline also suggests that discussion with the mother about the benefits and risks of expectant management is required if expectant management continues after 34 weeks of gestation.

Recently, several randomized controlled trials have been published that showed results contrary to those mentioned in the current guidelines. In these studies, no significant differences in the frequencies of perinatal complications were found between the expectant management and immediate delivery groups in late PPROM [9]. The incidence rate of complications of preterm delivery, such as respiratory distress syndrome, use of mechanical ventilation, and neonatal intensive care unit admission, was higher in the immediate delivery group [4]. It is expected that different management is practiced in various cases of late PPROM. Therefore, this study was conducted to investigate the current management of mothers with PPROM in Korea and to use the results as baseline data for national guidelines.

\section{Materials and methods}

\section{Questionnaire survey development and data collection}

A questionnaire survey was designed to examine the current management of women with PPROM in Korea, which was collaboratively conducted by the clinical practice guideline committee of the Korean Society of Maternal Fetal Medicine and the National Evidence-based Healthcare Collaborating Agency (NECA) in 2017 (Research No. NECA-C-17-004). First, the baseline characteristics of the respondents, including age, sex, clinical career duration, and the scale and location of the working hospital, were collected. Clinical career duration was divided into $<5,5-10,10-20,20-30$, and $>30$ years. The scale of the working hospital was divided into hospital, general hospital, and tertiary institution, and the location of the hospital was divided by province such as Seoul and Gyeonggi Province. Second, the respondents answered the questions on the first choice of antibiotic regimen in the cases of PPROM. The type of antibiotics they usually used was chosen, and multiple selections were possible. Third, the respondents also answered when they started and stopped using antenatal corticosteroids, and the first line of corticosteroids they usually used. Fourth, PPROM was classified as early PPROM (occurring before 34.0 weeks of gestation) and late PPROM (occurring between 34.0 and 36.6 weeks of gestation). In each group, the respondents answered the questions concerning the physicians' preference of delivery timing after 34.0 weeks of gestation (immediate delivery defined as induction of labor, cesarean section within 24 hours, and expectant management), the medical basis for each choice, and the factors influencing the determination of immediate delivery in PPROM patients. Finally, 5 factors that influenced the determination of immediate delivery were suggested, and the importance of each was indicated on a 4-point scale from 0 to 3 defined as follows: 0 , "wholly immaterial"; 1 , "immaterial"; 2, "important"; and 3, "very important."

\section{Data analysis}

Descriptive statistics was used for frequency distribution.

\section{Results}

A total of 113 obstetricians participated in the survey. Table 1 


\section{Obstetrics \& Gynecology Science}

Vol. 63, No. 3, 2020

showed the baseline characteristics of 112 obstetricians, excluding 1 obstetricians who did not respond to the basic information question. Among the respondents, $68.1 \%$ were female, and the mean age was 42.1 years. Overall, $31 \%$ had $<5$ years of experience, followed by $5-10$ years $(19.5 \%)$ and $10-20$ years $(28.3 \%)$, and $57.5 \%$ worked in tertiary hospitals. The working hospital of 93 of the 113 respondents were in Seoul or Gyeonggi Province.

In the case of PPROM occurring at $<37.0$ weeks of gestation, the most frequently prescribed antibiotics were cephalosporins and were used routinely by $92(81.4 \%)$ of the responding obstetricians, whereas $44(38.9 \%)$ of the respondents used penicillin and 44 (38.9\%) used macrolides. Among them, 39 (34.5\%) of the responding obstetricians

Table 1. Baseline characteristics of respondents $(n=112)$

\begin{tabular}{|c|c|c|}
\hline \multicolumn{2}{|l|}{ Characteristics } & \multirow{2}{*}{$\begin{array}{c}\text { Value } \\
42.1 \pm 8.6\end{array}$} \\
\hline Age (yr) & & \\
\hline \multirow[t]{2}{*}{ Sex } & Male & 35 (31.3) \\
\hline & Female & $77(68.7)$ \\
\hline \multirow[t]{5}{*}{ Clinical career period (yr) } & $<5$ & $35(31.3)$ \\
\hline & $5-10$ & $22(19.6)$ \\
\hline & $10-20$ & $32(28.6)$ \\
\hline & $20-30$ & $17(15.2)$ \\
\hline & $>30$ & $6(5.4)$ \\
\hline \multirow[t]{4}{*}{ Working hospitals scale } & Hospital & $30(26.8)$ \\
\hline & General hospital & $11(9.8)$ \\
\hline & Tertiary institution & $65(58.0)$ \\
\hline & Etc. & $6(5.4)$ \\
\hline \multirow[t]{12}{*}{ Location of the hospital } & Seoul & $49(43.8)$ \\
\hline & Incheon & $4(3.6)$ \\
\hline & Busan & $3(2.7)$ \\
\hline & Daegu & $1(0.9)$ \\
\hline & Ulsan & $2(1.8)$ \\
\hline & Gyeonggi & $44(39.3)$ \\
\hline & Gyeongbuk & $1(0.9)$ \\
\hline & Gyeongnam & $2(1.8)$ \\
\hline & Jeonbook & $2(1.8)$ \\
\hline & Gangwon & $1(0.9)$ \\
\hline & Jeju & $1(0.9)$ \\
\hline & Etc. & $2(1.8)$ \\
\hline
\end{tabular}

Data presented as mean \pm standard deviation or number (\%), and the numbers are rounded to one decimal place. reported to have prescribed cephalosporin alone and 14 $(12.4 \%)$ prescribed penicillin alone (Table 2 ).

The prevalence of corticosteroid use and the preferred limit of gestation of corticosteroid use are presented in Table 3 and Fig. 1. The prevalence of corticosteroid use in PPROM at $<37$ weeks of gestation was $88.5 \%$. According to the survey, corticosteroids were applied most frequently up to 34 weeks of gestation (50\%), followed by $36(16 \%)$ and 35 weeks (13\%) of gestation (Fig. 1). The prescribed corticosteroids were betamethasone (52\%) and dexamethasone (43\%; Table 3).

We also investigated the preferred treatment options of the attending physician when PPROM occurred at $<34.0$ weeks of gestation (early PPROM) and between 34.0 and

Table 2. Antibiotic of first choice in preterm premature rupture of membranes

\begin{tabular}{|c|c|}
\hline Characteristics & Value \\
\hline \multicolumn{2}{|l|}{ Frequency of prescribed antibiotics ${ }^{\mathrm{a})}$} \\
\hline Cephalosporin & 92 \\
\hline Ceftriaxone & 19 \\
\hline Cefazolin & 13 \\
\hline No answer & 34 \\
\hline Penicillin & 44 \\
\hline Amoxicillin & 12 \\
\hline Ampicillin, ampicillin sulbactam & 24 \\
\hline No answer & 11 \\
\hline Macrolide & 44 \\
\hline Azithromycin & 19 \\
\hline Clarithromycin & 19 \\
\hline Erythromycin & 1 \\
\hline No answer & 8 \\
\hline Metronidazole & 32 \\
\hline \multicolumn{2}{|l|}{$\begin{array}{l}\text { Prescription frequency according to antibiotic } \\
\text { combination administration }(n=109)^{b)}\end{array}$} \\
\hline One medicine single prescription & $53(48.6)$ \\
\hline Cephalosporin & $39(34.5)$ \\
\hline Penicillin & $14(12.5)$ \\
\hline In combination with penicillin or cephalosporin & $56(51.4)$ \\
\hline Plus macrolide & $28(25.0)$ \\
\hline Plus macrolide and metronidazole & $28(25.0)$ \\
\hline $\begin{array}{l}\text { Data presented as number, and multiple choice } \\
\text { presented as number (\%), and the numbers ar } \\
\text { decimal place. The total number of respondents is }\end{array}$ & $\begin{array}{l}\text { possible; }{ }^{b)} \text { r } \\
\text { unded to }\end{array}$ \\
\hline
\end{tabular}




\section{Obstetrics \& Gynecology Science}

Seo Yeon Kim, et al. Survey on the management of PPROM

36.0 weeks of gestation (late PPROM). The assumed conditions of the pregnant women were as follows: 1) absence of uterine contraction, 2) absence of medical/surgical disease or obstetrical problem, 3) absence of indication for cesarean section, and 4) absence of abnormal fetal conditions such as intrauterine growth restriction. When the gestational age reached 34.0 weeks in the early PPROM group, $71.3 \%$ of the responding obstetricians chose expectant management planning for delivery around term, whereas only $28.7 \%$ chose immediate delivery. In comparison for late PPROM, 57.41\% preferred expectant management and $42.59 \%$ preferred im-

Table 3. Corticosteroids of first choice in preterm premature rupture of membranes

\begin{tabular}{lc}
\hline Whether or not to use & Value \\
\hline Yes & $100(89.3)$ \\
Prescription type in use ${ }^{a)}$ & $52(52.0)$ \\
Betamethasone & $43(43.0)$ \\
Dexamethasone & $5(5.0)$ \\
Merging 2 types according to case & $11(9.8)$ \\
No & $1(0.9)$ \\
\hline
\end{tabular}

Data presented as number (\%), and the numbers are rounded to one decimal place.

a) The percentage in those who use antibiotics $(n=100)$ was presented. mediate delivery (Table 4).

The consideration factors for each subgroup in determining immediate delivery was also studied (Table 5). The most important determinants of immediate delivery were clinical signs and symptoms of chorioamnionitis, followed by abnormal findings on amniocentesis and maternal blood test.

\section{Discussion}

In this survey, $71.3 \%$ of the obstetricians favored expectant management and $28.7 \%$ chose immediate delivery when the gestational age reached 34.0 weeks in the early PPROM group. Approximately $37.5 \%$ and $58.1 \%$ of the responders who preferred expectant management in early and late PPROM, respectively, wanted to delay delivery until after 37.0 weeks of gestation. Among the responders who preferred immediate delivery, $65.6 \%$ answered that they made the decision due to concerns about ascending infection such as chorioamnionitis. These results suggested that actual decision making in clinical settings differs from the guidelines, which recommend immediate delivery in late PPROM and at 34.0 weeks in the early PPROM group.

The difference between the guidelines and our findings is quite remarkable [1]. The discrepancy between these results can be interpreted in 2 ways. First, some physicians with lon-

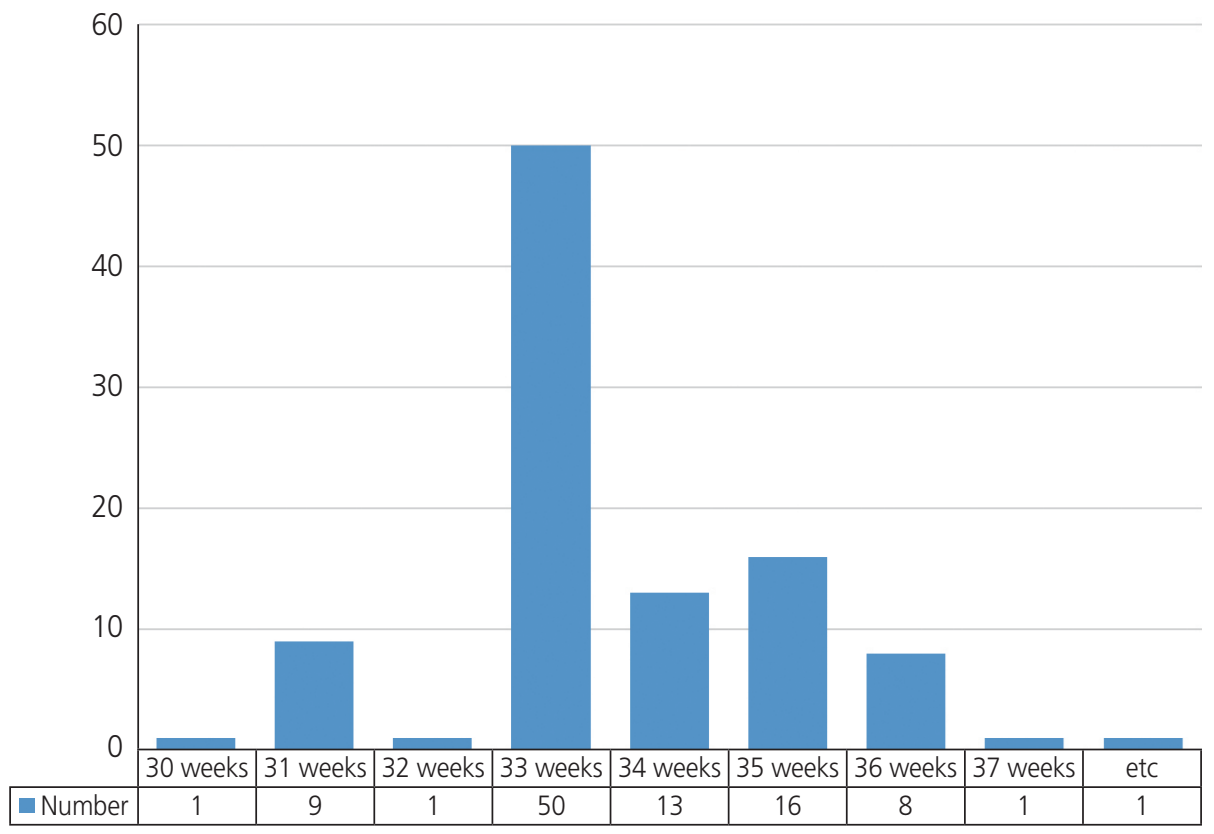

Fig. 1. The preferred limit of gestation when corticosteroids were administered. 


\title{
Obstetrics \& Gynecology Science
}

\author{
Vol. 63 , No. 3, 2020
}

ger duration of clinical experience tended to prefer expectant management than immediate delivery. Second, primary physicians may still not be fully acquainted with the guidelines for PPROM. This suggests that the guidelines need to

Table 4. Preferred management of preterm premature rupture of membranes (PPROM) after 34.0 weeks of gestation according to timing of PPROM (comparing between PPROM occurred before 34.0 weeks of gestation and after 34.0 weeks of gestation)

\begin{tabular}{|c|c|c|}
\hline Preferred management & $\begin{array}{l}\text { PPROM before } 34.0 \mathrm{wk} \\
(\mathrm{n}=108)\end{array}$ & $\begin{array}{c}\text { PPROM between } 34.0 \text { and } \\
36.6 \text { wk }(n=108)\end{array}$ \\
\hline \multicolumn{3}{|l|}{ Management plan for PPROM } \\
\hline Immediately delivery & $31(28.7)$ & $46(42.6)$ \\
\hline Expectant treatment & $77(71.3)$ & $62(57.4)$ \\
\hline \multicolumn{3}{|c|}{ Medical evidence of immediate delivery ${ }^{\mathrm{a})}$} \\
\hline Guideline & $5(15.6)$ & $9(19.6)$ \\
\hline Risk of mobidity and mortality & $21(65.6)$ & $23(50.0)$ \\
\hline Etc & $1(3.1)$ & $8(17.3)$ \\
\hline No answer & $5(15.6)$ & $6(13.04)$ \\
\hline \multicolumn{3}{|c|}{ Delivery timing ${ }^{\text {b) }}$ (weeks of gestation) } \\
\hline $34.0-34.6$ wk & $5(6.3)$ & $0(0.0)$ \\
\hline $35.0-35.6 w k$ & $14(17.5)$ & $10(16.1)$ \\
\hline $36.0-36.6 w k$ & $18(22.5)$ & $13(21.0)$ \\
\hline Over 37.0 & $30(37.5)$ & $36(58.1)$ \\
\hline Etc. & $13(16.3)$ & $0(0.0)$ \\
\hline No answer & $0(0.0)$ & $2(3.2)$ \\
\hline
\end{tabular}

Data presented as number (\%), and the numbers are rounded to one decimal place.

a)The respondents who chose 'immediately delivery' as the management for PPROM checked this questionnaire item. But one person who chose 'expectant treatment' check this questionnaire item in the 'PPROM before 34.0 weeks of gestation' $(n=32)$, whereas the respondents in the 'PPROM between 34.0 and 36.6 weeks of gestation' checked as intended $(n=46) ;$ b) The respondents who chose 'expectant management' as the management for PPROM checked this questionnaire item. But three persons who chose 'immediately delivery' check this questionnaire item in the 'PPROM before 34.0 weeks of gestation' $(n=80)$, whereas the respondents in the 'PPROM between 34.0 and 36.6 weeks of gestation' checked as intended ( $\mathrm{n}=62)$.

Table 5. The consideration factors that determine to change management of preterm premature rupture of membranes (PPROM) from expectant management to delivery according to timing of PPROM (comparing between PPROM occurred before 34.0 weeks of gestation and after 34.0 weeks of gestation)

\begin{tabular}{|c|c|c|c|c|c|c|c|c|c|c|}
\hline \multirow{2}{*}{$\begin{array}{l}\text { Consideration factor } \\
\text { Contribution score }^{\text {a) }}\end{array}$} & \multicolumn{5}{|c|}{ PPROM before 34.0 wk $(n=77)$} & \multicolumn{5}{|c|}{ PPROM between 34.0 and 36.6 wk $(n=62)$} \\
\hline & 0 & 1 & 2 & 3 & $\begin{array}{c}\text { No } \\
\text { answer }\end{array}$ & 0 & 1 & 2 & 3 & $\begin{array}{c}\text { No } \\
\text { answer }\end{array}$ \\
\hline $\begin{array}{l}\text { Reduced residual } \\
\text { amniotic fluid }\end{array}$ & $1(1.3)$ & $12(15.6)$ & $37(48.1)$ & $26(33.8)$ & $1(1.3)$ & $0(0.0)$ & $11(17.7)$ & $24(38.7)$ & $25(40.3)$ & $2(3.2)$ \\
\hline $\begin{array}{l}\text { Chorioamnionitis } \\
\text { symptoms }\end{array}$ & $0(0.0)$ & $0(0.0)$ & $0(0.0)$ & $76(98.7)$ & $1(1.3)$ & $0(0.0)$ & $0(0.0)$ & $1(1.6)$ & $59(95.2)$ & $2(3.2)$ \\
\hline Blood test result & $0(0.0)$ & $2(2.6)$ & $29(37.7)$ & $45(58.4)$ & $1(1.3)$ & $0(0.0)$ & $1(1.6)$ & $18(29.03)$ & $41(66.13)$ & $2(3.2)$ \\
\hline Amniocentesis result & $0(0.0)$ & $4(5.2)$ & $19(24.7)$ & $50(64.9)$ & $4(5.2)$ & $1(1.6)$ & $1(1.6)$ & $15(24.2)$ & $40(64.5)$ & $5(8.1)$ \\
\hline Maternal request & $4(5.2)$ & $20(26.0)$ & $40(51.9)$ & $12(15.6)$ & $1(1.3)$ & $2(3.2)$ & $16(25.8)$ & $31(50.0)$ & $11(17.7)$ & $2(3.2)$ \\
\hline
\end{tabular}

Data presented as number (\%), and the numbers are rounded to one decimal place.

a) Score from 0 to 3 presented the contribution to determine delivery (score 0: no contribution, score 1: less than moderate contribution, score 2: moderated contribution, and score 3: above moderate contribution). 


\section{Obstetrics \& Gynecology Science}

Seo Yeon Kim, et al. Survey on the management of PPROM

be revalidated, and the primary physicians must be educated about the verified revalidated guidelines.

The intravenous antibiotic regimen in the ACOG guideline is a combination of intravenous ampicillin and erythromycin [10-13]. However, there was variation in the choice of antibiotics. The most commonly used regimen $(34.5 \%)$ in our survey was cephalosporin monotherapy, followed by macrolides or macrolides plus metronidazole combined with penicillin or cephalosporin series.

In addition, many physicians appear to conduct corticosteroid therapies based on the latest knowledge [7-9]. The benefits of antenatal corticosteroids have been well established in preterm neonates in reducing the risk of neonatal respiratory distress, intraventricular hemorrhage, and neonatal death [2]. According to the latest guidelines, a single course of corticosteroids is recommended for pregnant women between 24.0 and 34.7 weeks of gestation. Furthermore, recent data suggest that administration of betamethasone in the late preterm period between 34.0 and 36.6 weeks reduces respiratory morbidity in newborns [1]. Moreover, they used dexamethasone and betamethasone almost in the same proportion as that used in this study.

There is great controversy about the choice of immediate delivery or expectant management in PPROM during 34.036.6 weeks of gestation. Some high-evidenced studies such as randomized clinical trials and meta-analyses on PPROM management have been published lately but could not provide a definite conclusion [10-12].

In the 2010 Cochrane review, it was concluded that the evidence on expectant management and immediate delivery was insufficient [14]. In 2016, the PPROMT trial published in Lancet reported that the immediate delivery group had more preterm-related complications, without significant differences in other outcomes [4]. The PPROMEXIL 1 and 2 trials of van der Ham et al. [15], reported in 2012, showed no significant differences in neonatal sepsis $(2.7 \%$ at 34.0 weeks vs. $4.1 \%$ at 37.0 weeks of gestation; relative risk [RR], 0.66 ; $95 \%$ confidence interval $[\mathrm{Cl}], 0.3-1.5)$ between 2 groups. However, induction of labor significantly reduced the risk of chorioamnionitis $(1.6 \%$ at 34.0 weeks vs. $5.3 \%$ at 37.0 weeks of gestation; RR, $0.31 ; 95 \% \mathrm{Cl}, 0.1-0.8)$. The 2018 ACOG guidelines pointed out that these studies did not have sufficient statistical power to show a significant reduction in the rate of neonatal sepsis because the overall rate of sepsis was lower than anticipated. More evidence-based studies with higher statistical power are required for the new guideline that supports expectant management in PPROM during 34.0-36.6 weeks of gestation [1].

So far, there is a lack of national studies on this theme. It is important to investigate our current management of PPROM for future research. The data presented are only from a questionnaire that reflects real practices. However, this study may facilitate establishment of future policy on PPROM management in Korea. This study has few limitations despite its significance. This survey did not include all obstetricians in Korea, and most participants worked around the capital area. Therefore, the results cannot be generalized.

In conclusion, the results of the questionnaire survey were as follows: 1) The most commonly used antibiotics was cephalosporin alone, followed by cephalosporin or penicillin plus macrolide or macrolide and metronidazole. 2) The corticosteroids were applied up to 34 weeks of gestation in half of the participants. 3) The frequency of expectant management was higher than that of immediate delivery in women with PPROM after 34 weeks of gestation. This may be interpreted as an attempt to improve the perinatal outcome by prolonging the gestational age in the absence of specific findings in the symptoms and laboratory findings of the mother. 4) The factors that influenced determination of delivery in the patients with PPROM were symptoms of chorioamnionitis, abnormal findings on amniocentesis, and blood test results.

Our data showed a considerable variation in the actual management of PPROM. It is thought that more evidence, including a randomized clinical trial, will be needed to narrow the gap between the current guideline and actual clinical practice

\section{Acknowledgments}

This study was supported by the National Evidence-based Healthcare Collaborating Agency (NECA-C-17-004).

\section{Conflict of interest}

No potential conflict of interest relevant to this article was reported. 


\section{Obstetrics \& Gynecology Science}

Vol. 63, No. 3, 2020

\section{Ethical approval}

The study was approved by the Institutional Review Board (IRB) of the National Evidence-based Healthcare Collaborating Agency (IRB No. NECA-C-17-004).

\section{Patient consent}

Written informed consent was collected from all subjects.

\section{References}

1. Committee on Practice Bulletins-Obstetrics. ACOG practice bulletin No. 188: prelabor rupture of membranes. Obstet Gynecol 2018;131:e1-14.

2. Bond DM, Middleton P, Levett KM, van der Ham DP, Crowther CA, Buchanan SL, et al. Planned early birth versus expectant management for women with preterm prelabour rupture of membranes prior to 37 weeks' gestation for improving pregnancy outcome. Cochrane Database Syst Rev 2017;3:CD004735.

3. Chandra I, Sun L. Third trimester preterm and term premature rupture of membranes: is there any difference in maternal characteristics and pregnancy outcomes? J Chin Med Assoc 2017;80:657-61.

4. Morris JM, Roberts CL, Bowen JR, Patterson JA, Bond $\mathrm{DM}$, Algert CS, et al. Immediate delivery compared with expectant management after preterm pre-labour rupture of the membranes close to term (PPROMT trial): a randomised controlled trial. Lancet 2016;387:444-52.

5. Ramsey PS, Nuthalapaty FS, Lu G, Ramin S, Nuthalapaty ES, Ramin KD. Contemporary management of preterm premature rupture of membranes (PPROM): a survey of maternal-fetal medicine providers. Am J Obstet Gynecol 2004;191:1497-502.

6. Goldenberg RL, Nelson KG, Davis RO, Koski J. Delay in delivery: influence of gestational age and the duration of delay on perinatal outcome. Obstet Gynecol
1984;64:480-4.

7. Ekin A, Gezer C, Taner CE, Ozeren M, Uyar I, Gulhan I. Risk factors and perinatal outcomes associated with latency in preterm premature rupture of membranes between 24 and 34 weeks of gestation. Arch Gynecol Obstet 2014;290:449-55.

8. Tsakiridis I, Mamopoulos A, Chalkia-Prapa EM, Athanasiadis A, Dagklis T. Preterm premature rupture of membranes: a review of 3 national guidelines. Obstet Gynecol Surv 2018;73:368-75.

9. van Teeffelen AS, van der Ham DP, Willekes C, Al Nasiry S, Nijhuis JG, van Kuijk $S$, et al. Midtrimester preterm prelabour rupture of membranes (PPROM): expectant management or amnioinfusion for improving perinatal outcomes (PPROMEXIL - III trial). BMC Pregnancy Childbirth 2014;14:128.

10. Kenyon S, Boulvain M, Neilson JP. Antibiotics for preterm rupture of membranes. Cochrane Database Syst Rev 2013:CD001058.

11. American College of Obstetricians and Gynecologists' Committee on Practice Bulletins-Obstetrics. Practice bulletin No. 172: premature rupture of membranes. Obstet Gynecol 2016;128:e165-77.

12. Randis TM, Polin RA, Saade G. Chorioamnionitis: time for a new approach. Curr Opin Pediatr 2017;29:159-64.

13. Siegel AM, Heine RP, Dotters-Katz SK. The effect of nonpenicillin antibiotic regimens on neonatal outcomes in preterm premature rupture of membranes. AJP Rep 2019;9:e67-71.

14. Buchanan SL, Crowther CA, Levett KM, Middleton P, Morris J. Planned early birth versus expectant management for women with preterm prelabour rupture of membranes prior to 37 weeks' gestation for improving pregnancy outcome. Cochrane Database Syst Rev 2010:CD004735.

15. van der Ham DP, van der Heyden JL, Opmeer BC, Mulder AL, Moonen RM, van Beek JH, et al. Management of late-preterm premature rupture of membranes: the PPROMEXIL-2 trial. Am J Obstet Gynecol 2012;207:276. e1-10. 